\title{
El ascenso de China y sus efectos en la relación con Argentina*
}

\author{
The rise of China and its effects \\ on relations with Argentina
}

\author{
Eduardo Daniel Oviedo**
}

\section{Resumen}

Tres lustros después de que China se convirtiera en gran potencia económica, es un tiempo apropiado para evaluar los efectos que el nuevo rol internacional del país asiático generó en Argentina. Por eso, el presente artículo examina cómo la modernización económica en China y su nuevo rol internacional dieron forma a intereses armónicos entre las partes, que integraron a Argentina en la cadena de producción global de China, como proveedora de soja e importador de manufacturas. Como resultado, crecieron el comercio y las inversiones chinas en Argentina, se amplió la brecha Norte-Sur y consolidó el status periférico del país sudamericano en el modelo centro-periferia que prevalece en la relación. El eje de este modelo estuvo basado en la «primarización sojera», y en la actualidad transita hacia la "primarización agrícola diversificada», con el objeto de revertir los déficits de balanza comercial iniciados en 2008.

Palabras clave: Relaciones Norte-Sur; relaciones argentino-chinas; primarización; relaciones centro-periferia

* Investigación realizada dentro del marco del programa de postdoctorado de la Universidad Nacional de Rosario, Argentina.

** Profesor titular de historia de las relaciones internacionales contemporáneas, Universidad Nacional de Rosario, Argentina. eduardodanieloviedo@hotmail.com Recibido el 4 de agosto de 2014; aceptado el 15 de diciembre de 2014. 


\section{Abstract}

Fifteen years after China became a major economic power is an appropriate time to evaluate the effects that the new international role of this Asian country has had in Argentina. Hence, this paper examines how economic modernization in China and its new role in the international system shaped harmonic interests between both sides, which integrated Argentina into Chinese global production chain as a supplier of soybean and importer of manufactured goods. As a result, trade exchange and Chinese investments in Argentina grew, although it extended the North-South gap and consolidated the peripheral status of this South American country in the core-periphery model that prevails in the relationship. The axis of the model was based on the "soybean primarization" and now moves toward the «diversified agricultural primarization", in order to reverse the trade deficit that began in 2008 .

KEYwords: North-South relations; Argentine-Chinese relations; primarization; Core-periphery relations 


\section{INTRODUCCIÓN}

El ascenso de China en la estructura de poder internacional es un tema tratado asiduamente en la bibliografía de las relaciones internacionales. Su razón alberga en que la potencia asiática logró este objetivo a partir de decisiones de políticas internas y externas, aplicadas desde la Guerra Fría, las que produjeron el salto cualitativo de mediana a gran potencia a fines del siglo XX, ingresando como miembro del Directorio de grandes potencias ${ }^{1} \mathrm{y}$ acrecentando su poder nacional integral ${ }^{2}$ en forma

$1 \quad$ El oligopolio de poder está compuesto por las grandes potencias que ejecutan políticas mundiales y cuentan con capacidad para administrar el orden internacional. Por eso, el Directorio es visto como la administración mancomunada de la política mundial por los grandes poderes. Esta práctica apareció institucionalizada con la creación del sistema periódico de reuniones entre las grandes potencias, iniciado con el Congreso de Viena de 1815 , pero data de la misma formación del sistema internacional, durante la Paz de Westfalia. Los resultados de la estratificación económica de los Estados a partir del uso del criterio de Pareto (Oviedo, 2005: 49-50), permite aseverar que el oligopolio se corresponde con los Estados centrales de la teoría de la economía-mundo, si bien las categorías de Wallerstein focalizaban más en las áreas desarrolladas que en los Estados. No obstante dicho análisis reconoce las diferencias existentes entre el pensamiento de Wallerstein y el realismo político.

2 El poder nacional integral es un concepto chino que aporta a la teoría de las relaciones internacionales, denominado en chino 综合国力 (zonghe guoli) y en inglés comprehensive national power. Huang continua hasta el presente. Esta transformación -junto a la de otras unidades políticas- alteró la estructura de poder configurada tras la desintegración soviética, repercutiendo en todos los ámbitos del sistema internacional.

Argentina no quedó al margen de sus efectos. Los cambios en el orden internacional resultaron importantes para los Estados periféricos ${ }^{3}$ y su adaptación al nuevo esquema de poder. Inmersos en la segunda década del siglo XXI -y a tres lustros de que el país asiático eliminara su situación colonial y accediera al Directorio de grandes potencias- suficiente es el tiempo transcurrido para estimar los resultados que el nuevo rol de China en la política internacional originó en las relaciones entre Estados. Por eso, el presente estudio investiga los efectos que el nuevo estatuto de China en la política internacional produjo en los vínculos con los países periféricos, atendiendo a las relaciones argentinochinas.

Shuo Feng (1992) ha desarrollado en extenso este concepto.

3 El economista Ernst Wagemann utilizó, por primera vez, el concepto periferia (Bernal-Meza, 2005: 79). Raúl Prebisch introdujo la relación centro-periferia en el ámbito económico internacional y otros autores latinoamericanos continuaron su estudio. En la década de 1970, Immanuel Wallerstein (1996: 492) incluyó a la semiperiferia como una fuerza intermedia entre el centro y la periferia. Este artículo asocia dichos conceptos como calificativos del término estado, si bien Wallerstein utilizó las nociones de estados centrales y áreas periféricas y semiperiféricas. 
La afirmación preliminar considera que la modernización económica en China y su nuevo rol internacional dieron forma a intereses complementarios que integraron a la Argentina en la cadena de producción global del país asiático, con el rol de proveedor de soja y sus derivados e importador de manufacturas. Como resultado, creció el comercio bilateral y se diversificaron los destinos comerciales, mientras que la diferencia de crecimientos económicos agudizó las asimetrías que consolidaron el modelo Norte-Sur, así como también el status periférico de Argentina en el modelo centro-periferia que prevalece en el intercambio comercial. Este esquema predomina en la primarización sojera de sus exportaciones (actualmente en tránsito hacia la primarización agrícola diversificada); crónicos déficits comerciales y obstáculos a su industrialización. A su vez, la mayor interacción económica fortaleció la influencia política de la potencia asiática en Argentina y generó una orientación externa proclive a la República Popular China, especialmente en materia de derechos humanos y la cuestión de Taiwán; al tiempo que genera dependencia comercial y financiera, precaria en los actuales niveles de interrelación.Efectos en países periféricos: el caso argentino

El ascenso de China en la política internacional generó los siguientes efectos en Argentina: a) armonía comercial; b) reedición del modelo centro-periferia y primarización sojera; c) inicio de la transición hacia la primarización agrícola diversificada; d) emergencia de déficits comerciales; e) generación de obstáculos a la industrialización; f) desconcentración de los destinos comerciales y mitigación de riesgos; g) cambio en la corriente de inversiones y expansión de las inversiones chinas en Argentina; h) ampliación de la brecha asimétrica y formación de relaciones Norte-Sur; i) creciente influencia china y debilitamiento del vínculo con Taiwán; j) política proclive a China en derechos humanos; k) deterioro del comercio intra-zona y otros efectos indirectos vía Mercosur. Además, existen otras consecuencias vinculadas a cuestiones políticas, sociales, culturales y migratorias no tratadas en el presente artículo, pues el mismo se concentra en las cuestiones comerciales y financieras y su impacto en la política bilateral. A continuación pasamos a analizar cada uno de estos efectos.

\section{a) Armonía comercial}

$\mathrm{Al}$ igual que Argentina, China poseía una economía eminentemente agraria. Similares estructuras y el atraso económico chino impidieron armonizar intereses comerciales durante la Guerra Fría, excepto ante situaciones de emergencia, cuando erróneas decisiones en el plano interno o magras cosechas en China habilitaban la importación de granos, como ocurrió durante la presidencia de Arturo Illia (1963-1966). Estas situaciones fueron mitigadas con la política de autosuficiencia agrícola, alcanzada a inicios de la década de los años setenta, coincidente con el inicio 
del vínculo oficial con la República Popular China. Si bien sus autoridades continuaron esta política, el avance de la industrialización diferenció las estructuras, lo que unido a la superpoblación, la expansión de la demanda y los límites de la frontera agraria, forzaron la reapertura de canales adicionales de abastecimiento agrícola.

La modificación de la estructura económica china expandió el comercio bilateral a partir de la inserción de Argentina en su circuito de capital, producción y mercado a escala global. En su primera fase, iniciada con la apertura económica a fines de los años setenta, el circuito se caracterizó por el arribo de inversiones extranjeras a China, que en condiciones ventajosas otorgadas por el gobierno comunista, crearon empresas de capital exclusivo o joint ventures para producir en zonas especiales y exportar al mundo. En esta fase, el comercio bilateral creció de manera sostenida a volúmenes no relevantes y la corriente de inversiones fue sumamente escasa, con algunas empresas argentinas (Impsa, Siderca) con proyectos en China.

En 1989, la represión de la Plaza Tiananmen interrumpió esta fase. La economía china quedó estancada y la incertidumbre cernía sobre qué política seguiría el Partido Comunista. Argentina, atendiendo a sus intereses comerciales, bajo el principio de no intervención en asuntos internos estipulado en la declaración conjunta de 1972, mantuvo estable la relación, a pesar de la turbulencia internacional sobre la cuestión de los derechos humanos en ese país. En 1991, la potencia asiática retoma el sendero de crecimiento acelerado que mantendrá constante durante las próximas décadas.

El inicio de la segunda fase coincide con la política de convertibilidad en Argentina (1991-2002), momento en que China se transforma en socio cada vez más relevante del país sudamericano. Entrado el siglo, mientras la convertibilidad fracasa en Argentina, los altos niveles de productividad china encuentran deficiente la oferta interna de materias primas y comienza a importarlas desde el exterior. Al mismo tiempo, expande su deprimido mercado interno, que si bien en términos de población siempre fue importante, no lo era en consumo. Es en esta fase cuando Argentina consolida su inserción en el modelo productivo chino como proveedora de materias primas, con nichos de exportaciones industriales y compra de manufacturas.

Esta complementariedad es un ejemplo claro de lo que el profesor Robert Keohane denominó «armonía». Según este autor, la armonía «refiere a una situación en la que las políticas de los actores (concretadas en su propio interés sin consideraciones por el interés de los demás) automáticamente facilitan el logro de los propósitos de los otros» (Keohane, 1988: 71). Es decir, sin quererlo, China estimuló a la economía argentina y favoreció el logro de los objetivos de ambas partes, pues el país sudamericano incrementó sus ventas, al tiempo que garantizó a China el suministro de una cuota de bienes estratégicos para su seguridad 
alimentaria, energética e insumos para producir bienes que la «fábrica» china destina a la exportación o al consumo interno. En principio, se trata de una relación win-win, con crecimiento vertiginoso del comercio bilateral (ver cuadro $\mathrm{N}^{\circ} 2$ ) y tendencia creciente del volumen de las inversiones.

\section{b) Reedición del modelo centro- periferia y primarización sojera}

A pesar de los beneficios comunes y la mayor densidad en la relación, el modelo de la armonía profundizó el intercambio centro-periférico y primarizó las exportaciones del país sudamericano. El comercio tiene eje en las ventas argentinas de porotos de soja, algunos de sus derivados, aceite crudo de petróleo y otras materias primas; mientras que China exporta manufacturas y equipos. Dado estos componentes del vínculo comercial, cuya expresión más representativa es el «trueque» soja por trenes, el patrón de interacción reedita la relación centro-periférica, experimentada por Argentina y Gran Bretaña desde fines del siglo XIX hasta la crisis de 1929. Para Argentina, otrora era el trigo; hoy es la soja.
Cuadro $N^{\circ} 1$ : Componentes del comercio bilateral - Año 2012.

\begin{tabular}{|l|r|r|}
\hline Exportaciones & 5.021 & $100 \%$ \\
\hline Poroto de soja & 2.722 & $54.2 \%$ \\
\hline Aceite de soja en bruto & 851 & $17.0 \%$ \\
\hline Petróleo crudo & 600 & $11.9 \%$ \\
\hline Pieles y cueros & 105 & $2.0 \%$ \\
\hline Resto & 743 & $14.8 \%$ \\
\hline
\end{tabular}

\begin{tabular}{|l|r|r|}
\hline Importaciones & 9.951 & $100 \%$ \\
\hline $\begin{array}{l}\text { Circuitos impresos para } \\
\text { aparatos eléctricos de } \\
\text { telefonía }\end{array}$ & 630 & $6.3 \%$ \\
\hline $\begin{array}{l}\text { Partes para aparatos } \\
\text { eléctricos de telefonía }\end{array}$ & 538 & $5.4 \%$ \\
\hline $\begin{array}{l}\text { Partes para aparatos } \\
\text { receptores de telefonía }\end{array}$ & 383 & $3.9 \%$ \\
\hline Glifosato & 305 & $3.1 \%$ \\
\hline Resto & 8.095 & $81.3 \%$ \\
\hline
\end{tabular}

Fuente: Instituto Nacional de Estadísticas $y$ Censos (INDEC), Anuario de Comercio Exterior, Buenos Aires, 2012.

En millones de dólares estadounidenses.

Este esquema se repite en el resto de Sudamérica. Incluso existe una doble especialización: la región produce materias primas y cada país se especializa en uno o dos productos. Esta estrategia es deliberada, en la medida en que China no desea la prosperidad económica de Sudamérica sino el control de sus canales de abastecimiento. Esto no sucede con la soja, donde Argentina, Brasil y Estados Unidos oligopolizan la oferta frente al monopsonio chino de la demanda, si bien en los últimos años India, Irán, Egipto y España tienen mayor participación en las ventas del país sudamericano. El ingreso de COFCO (China National Cereals, Oils and Foodstuffs Corporation) como 
nuevo actor en el mercado de semillas y granos, a partir de la compra del 51 por ciento del paquete accionario de la transnacional Nidera, tiende a mitigar esta escasa presencia china y busca controlar la oferta de granos, en el contexto de creciente participación de las compras chinas.

La demanda de la potencia asiática, el alza del precio mundial de la soja y el cambio tecnológico (especialmente de la mano de la siembra directa y las compras chinas de soja transgénica) ampliaron la participación de la agricultura en la economía nacional, en detrimento del sector servicios. Notoriamente observable tras la crisis de 2001-2002, cuando el sector pasó del estable 5\% entre 1992 y 2001 al $8.1 \%$ en promedio entre 2002 y 2012 , con pico del $10 \%$ en 2003. Es decir, más allá de los beneficios monetarios provenientes de la venta de commodities y los discursos oficiales sobre la des-primarización económica, la agricultura incrementó su participación en la economía nacional, estimulada por la venta de soja en grano, donde China es el importador más destacado, con $86.2 \%$ del total en 2012 .

\section{c) Transición hacia la primarización agrícola diversificada}

Ante esta situación, común en Latinoamérica, la Cepal recomendó diversificar las exportaciones destinadas al mercado chino, para que «la dinámica del comercio y las inversiones Sur-Sur no acentúe el patrón tradicional de inserción de las economías latinoamericanas en la división internacional del trabajo» (Cepal, 2013: 48).

Más allá de la visión errónea del informe, en el sentido de considerar las relaciones chino-latinoamericanas en el esquema Sur-Sur, Argentina ha sido un ejemplo de diversificación, en la medida en que desde mediados de la primera década del siglo, a las exportaciones de porotos de soja, aceite de soja y aceite de petróleo (que según la cuadro $\mathrm{N}^{\circ} 1$ representaron el $83.1 \%$ del total exportado a China en 2012) sumó la firma de protocolos sanitarios para el acceso al mercado chino de tabaco, peras, manzanas, cebada, maíz, sorgo y otros agro-commodities. Excepto en tabaco y aceites de maní y girasol, el resto de los productos aún no ha tenido acceso o sus volúmenes son insignificantes. Sin embargo, cabe destacar que esta expansión de las exportaciones es horizontal, basada en productos primarios o de escaso valor agregado y no de carácter vertical, sin atender a la agregación de valor a través de la industrialización.

Este es el eje central del «choque de modernizaciones», es decir, la guerra por agregar valor industrial o tecnológico. China es la «fábrica del mundo» y mantiene a América Latina como proveedora de materias primas, región a la cual imprime una política común. Por eso, la mera diversificación de la oferta latinoamericana, tal como lo pide la Cepal, no es una condición sine qua non para no acentuar el patrón tradicional de comercio latinoamericano. 
Por el contrario, la diversificación horizontal profundiza este esquema. A fin de revertir esta situación y reorientar los commodities hacia la industrialización, Argentina aplicó gravámenes a la exportación de soja y otros cultivos desde 2002, aunque las administraciones de Néstor Kirchner y Cristina Fernández de Kirchner centraron los esfuerzos en la faz recaudatoria del impuesto y una enunciada distribución populista de la riqueza.

\section{d) Emergencia de déficits comerciales}

Desde la normalización diplomática de 1972, Argentina tuvo 21 años ininterrumpidos de superávits comerciales con China. El inicio de la política de la convertibilidad revirtió esta tendencia y desde 1992 el saldo negativo fue anualmente constante. En 2001 cambia la tendencia, con saldos favorables hasta 2007. Sin embargo, a contar de 2004 estos superávits decrecieron y en 2008 registraron déficit, generando una nueva tendencia de saldos favorables chinos, anualmente constantes y crecientes. Es decir, si bien el comercio bilateral decuplicó entre 2002 y 2010, pasando de 1.417 millones de dólares a 13.448 millones (y siguió creciendo hasta 17.347 en 2013), entre 2002 y 2012 fue deficitario para Argentina en 6.893 millones, y 12.270 millones si se incluye 2013. Solamente en este último año el superávit chino ascendió a 5.377 millones (ver cuadro $\mathrm{N}^{\circ} 2$ ). Entre 2008 y 2013 el déficit trepó a 17.968 millones, representando una cifra similar a la caída de las reservas argentinas en el mismo periodo.

Cuadro N²: Comercio argentino-chino (2002-2013).

\begin{tabular}{|c|c|c|c|c|}
\hline Año & Exportaciones & Importaciones & Total & Saldo \\
\hline 2002 & 1.088 & 329 & 1.417 & +759 \\
\hline 2003 & 2.451 & 720 & 3.171 & +1.731 \\
\hline 2004 & 2.628 & 1.402 & 4.030 & +1.226 \\
\hline 2005 & 3.336 & 2.270 & 6.489 & +1.066 \\
\hline 2006 & 3.646 & 3.153 & 6.799 & +493 \\
\hline 2007 & 5.166 & 5.092 & 10.258 & +74 \\
\hline 2008 & 6.397 & 7.104 & 13.501 & -707 \\
\hline 2009 & 3.668 & 4.823 & 8.491 & -1.155 \\
\hline 2010 & 5.799 & 7.649 & 13.448 & -1.850 \\
\hline 2011 & 6.173 & 10.573 & 16.746 & -4.400 \\
\hline 2012 & 5.165 & 9.952 & 15.117 & -4.787 \\
\hline 2013 & 5.985 & 11.362 & 17.347 & -5.377 \\
\hline Total & 51.502 & 64.429 & 115.931 & -12.927 \\
\hline
\end{tabular}

Fuente: INDEC Informa, 2003-2014.

Unidad: millones de dólares estadounidenses. Excluidos Hong Kong, Macao y Taiwán. 
Eduardo Daniel Oviedo

El ascenso de China y sus efectos en la relación con Argentina *

Este periodo deficitario se suma a la etapa entre 1992-2002, en que el saldo desfavorable alcanzó a 2.378 millones de dólares. Algo distinto a lo sucedido en las décadas anteriores (ver cuadro $\mathrm{N}^{\circ} 3$ ). su economía y encontró a China, país que no era acreedor de su deuda pública o privada, como proveedor alternativo de bienes que otrora importaba desde otros países (por ejemplo, la compra de material rodante ferroviario que antes

Cuadro N³: Comercio bilateral entre Argentina y China.

\begin{tabular}{|l|r|r|r|r|}
\hline Rubro & $1972-1982$ & $1982-1992$ & $1992-2002$ & $2002-2012$ \\
\hline Exportaciones a China & 896 & 2.926 & 6.485 & 45.112 \\
\hline Importaciones desde China & 80 & 311 & 8.863 & 53.006 \\
\hline Comercio total & 976 & 3.237 & 15.348 & 98.118 \\
\hline Saldo comercial & +816 & +2.615 & -2.378 & -6.893 \\
\hline $\begin{array}{l}\text { Porcentaje del déficit sobre el } \\
\text { comercio total }\end{array}$ & & $15,5 \%$ & $8,0 \%$ \\
\hline
\end{tabular}

Fuente: INDEC Informa.

Unidad: millones de dólares estadounidenses.

Excluidos Hong Kong, Macao y Taiwán.

En el mismo periodo, Brasil y Chile registraron superávits de $30.253 \mathrm{mi}$ llones de dólares y 39.000 millones de dólares, respectivamente. Otra economía abierta como Perú generó un saldo favorable de 4.131 millones; mientras que Venezuela de 10.568 millones. Solo Uruguay ha sido otro ejemplo de déficit con China en el mismo periodo (ver cuadro $\mathrm{N}^{\circ} 4$ ).

Esta desfavorable situación puede ser entendida por los siguientes factores: 1) en el caso de Brasil, la oferta primaria exportadora contó, además de la soja, con las exportaciones de mineral de hierro; 2) en el caso de Chile (y también Brasil) la diferencia en el incremento del valor del cobre (y el mineral de hierro) respecto de la soja; 3) el default argentino de 2001 aisló a era provisto por países europeos o Japón), favorecido por el financiamiento que China otorga; 4) la inflación interna retrasó el tipo de cambio y dificultó la exportación, al tiempo que facilitó la importación de productos, situación agravada con el control de cambio impuesto a partir de octubre de $2011 ; 5$ ) el autoabastecimiento chino en harina de soja y la creciente disminución de las compras de aceite, como consecuencia del mayor crushing ${ }^{4}$ del poroto de soja en China, a partir del plan de inversiones en el sector y la importación de soja en grano desde Estados Unidos y Brasil.

4 «En la industria sojera el término «crush» o «crushing» indica el proceso físico de convertir el poroto de soja en subproductos, tal el caso del aceite y la harina de soja» (Perotti, 2008: 1) 
Cuadro $N^{\circ} 4$ : Comercio bilateral entre China y algunos países sudamericanos.

\begin{tabular}{|l|r|r|r|r|r|r|}
\hline \multicolumn{1}{|c|}{ 2002-2012 } & \multicolumn{1}{c|}{ Argentina } & \multicolumn{1}{c|}{ Brasil } & \multicolumn{1}{c|}{ Chile } & \multicolumn{1}{c|}{ Perú } & \multicolumn{1}{c|}{ Uruguay } & \multicolumn{1}{c|}{ Venezuela } \\
\hline $\begin{array}{l}\text { Exportaciones a } \\
\text { China }\end{array}$ & 45.112 & 192.211 & 102.247 & 37.765 & 2.652 & 39.615 \\
\hline $\begin{array}{l}\text { Importaciones } \\
\text { desde China }\end{array}$ & 53.006 & 161.958 & 63.247 & 33.634 & 7.419 & 29.047 \\
\hline Comercio total & 98.118 & 364.159 & 165.494 & 71.399 & 10.071 & 68.662 \\
\hline Saldo comercial & -6.893 & 30.253 & 39.000 & 4.131 & -4.767 & 10.568 \\
\hline
\end{tabular}

Fuente: Centro de Economía Internacional, Argentina. Unidad: millones de dólares estadounidenses. Excluidos Hong Kong, Macao y Taiwán.

Las exportaciones argentinas crecieron entre 2002 y 2007, estancándose a partir de ese año y manteniendo constante su valor en el quinquenio 2008-2013, con un retroceso abrupto en 2009. Aun con altos precios del poroto y aceite de soja, Argentina fue incapaz de incrementar las ventas y generar superávits en el comercio bilateral, como ocurrió con otras naciones sudamericanas. Si bien la política de sustitución de importaciones de Fernández de Kirchner mantuvo superávit en el comercio total de Argentina, según el Banco Mundial, las ventas al exterior en relación al PIB pasaron del estable $25 \%$ entre 2003 y 2008 , al $15 \%$ en 2013; mientras que las exportaciones hacia China cayeron del $8.7 \%$ en 2003 al $7.2 \%$ en 2013 . Las importaciones, netamente industriales, crecieron constantes desde 2002 y duplicaron las ventas argentinas en 2012 y 2013.

\section{e) Obstáculos a la industrialización}

La competitividad de las manufacturas chinas representó un obstáculo al proceso de industrialización argentino. Los gobiernos intentaron contener la corriente de importaciones de productos chinos con medidas antidumping y otros mecanismos de manipulación para el acceso a mercado, incluso la reedición del modelo de sustitución de importaciones desde 2008. A la inversa, China tampoco estuvo dispuesta a importar productos con valor agregado, en tanto ellos puedan ser industrializados en su territorio. El ejemplo clásico es la preferencia por el poroto a las harinas y pellets de soja, a pesar de que sus valores agregados son escasos. Otro es el maíz. Si bien las autoridades chinas han habilitado su importación en 2012, la mora en la aprobación de un evento transgénico imposibilitó la exportación de este grano a China. De esta manera, la armonía de intereses coexistió con tensiones comerciales que debieron ser resueltas mediante la cooperación entre las partes, siendo la interrupción de las importaciones de aceite de soja en 2010 su ejemplo más representativo (Oviedo, 2012a). China crea redes de intereses complementarios con los países ricos en recursos naturales, aunque si estos 
países están dispuestos a des-primarizar sus economías simultáneamente emerge la discordia. Esta es consecuencia del «choque de industrializaciones», propio del interés contradictorio de desarrollar procesos de modernización en China y Latinoamérica.

f) Desconcentración de los destinos comerciales y mitigación de riesgos

La desconcentración económica mundial diversificó los destinos comerciales de los países. Argentina no quedó fuera de esta tendencia. En 1960, el país concentró sus exportaciones en Europa, y en menor medida Estados Unidos y Brasil, representando más del $80 \%$ de las ventas externas. Según el INDEC, ese año Europa -excluida la Europa soviética- significó $64,4 \%$; Estados Unidos 8,5\% y Brasil 7,7\%.

La Comunidad Económica Europea -y su continuadora la Unión Europea- creó una red interna de subsidios agrícolas que restringió las compras externas de productos agropecuarios; al tiempo que Estados Unidos, siempre presente como uno de los socios comerciales, poseía -y aún posee- una economía competitiva que impedía una mayor complementación con Argentina. Ante el acotamiento de mercados, algunos gobiernos -como los de Illia, Lanusse, Perón y Videla- aprovecharon la distensión internacional para atravesar lo que Ferrari (1983: 85) denominó las «barreras ideológicas» del bipolarismo y entablar vínculos comerciales con países comunistas, como China Popular. No obstante, su mayor logro fue la exportación de cereales a la
Unión Soviética entre 1980 y 1985, con su pico más álgido en 1981, cuando representó el 32.4\% del total exportado.

Los países europeos dejaron paso a Estados Unidos y Brasil, y en las dos últimas décadas, también a Chile y China. Tras la distensión política promovida por el acuerdo Alfonsín-Sarney de 1985, Brasil pasó a ser socio comercial principal, concentrando entre un cuarto y un tercio de las ventas externas. India, Rusia y Corea del Sur incrementaron sus importaciones sin ingresar entre los diez primeros destinos o aparecieron esporádicamente en algunos años, al igual que Japón, un emergente de los años setenta. En 2013, Argentina contó con cuatro de las diez primeras economías ${ }^{5}$ entre los primeros diez destinos de sus exportaciones: los tres primeros, Brasil $(21,5 \%)$, China $(7,2 \%)$ y Estados Unidos $(5,1 \%)$; mientras Alemania $(2,2 \%)$ se posicionó en el octavo puesto ${ }^{6}$.

En 1960, cinco de los diez primeros destinos comerciales eran europeos, en especial los tres primeros; mientras que en 2010 cuatro países de ese continente ocuparon desde el quinto al octavo lugar y los cuatro primeros fueron dos sudamericanos (Brasil y Chile), uno asiático (China) y otro de América del

5 Conforme al PIB a precios actuales publicado por el Banco Mundial, las diez primeras economías en 2013 fueron: Estados Unidos, China, Japón, Alemania, Francia, Reino Unido, Brasil, Federación Rusa, Italia e India.

6 Según el Banco Mundial, en 2013 las diez primeras economías fueron: Estados Unidos, China, Japón, Alemania, Francia, Gran Bretaña, Brasil, Rusia, Italia e India. 
Norte (Estados Unidos). España se posicionó recién como quinto destino, con el 3,5\% de las exportaciones totales. Las compras chinas, no obstante su importancia, aún distan mucho de superar las exportaciones argentinas a la Unión Soviética el primer quinquenio de 1980 .
Los destinos de las exportaciones por continente muestran la decadencia estructural de Europa y el ascenso de Asia, en el cual China cumple un rol importante. En 2007, por primera vez en la historia bilateral, Asia superó a Europa como segundo destino de las exportaciones argentinas. En 2013, China representó el 59.4\% de las ventas asiáticas y el $28.8 \%$ de las compras desde dicho continente. Sin embargo, es más relevante la americanización de los destinos, representando este continente aproximadamente el $50 \%$ de las exportaciones totales.

\section{Cuadro No5: Evolución histórica de los cinco principales} destinos de las exportaciones de Argentina.
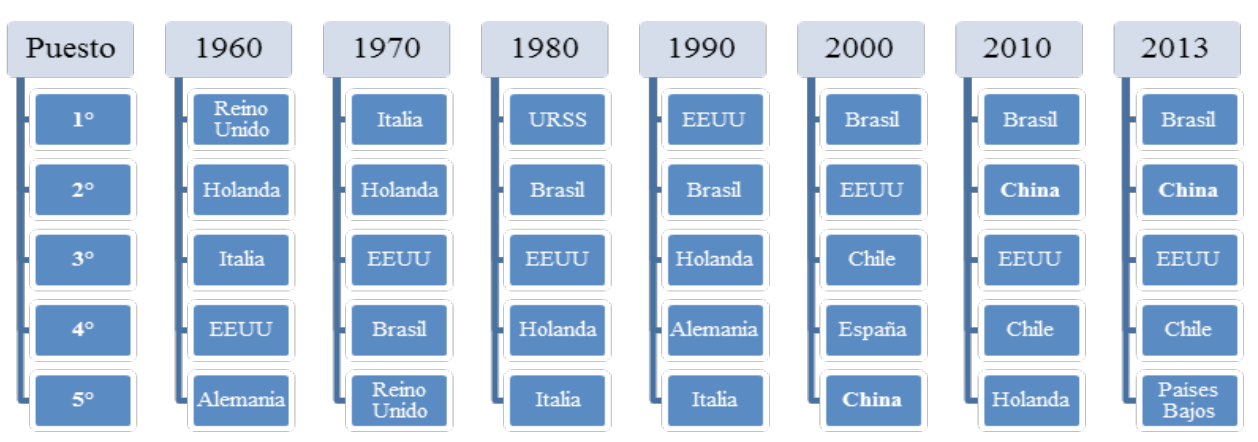

Cuadro $N^{\circ}$ : Porcentaje de las exportaciones argentinas por continentes.

\begin{tabular}{|c|r|r|r|r|r|r|}
\hline Continente & \multicolumn{1}{|c|}{1970} & \multicolumn{1}{|c|}{1980} & \multicolumn{1}{c|}{1990} & \multicolumn{1}{c|}{2000} & \multicolumn{1}{c|}{2010} & \multicolumn{1}{c|}{2013} \\
\hline América & $30.4 \%$ & $33.9 \%$ & $42.0 \%$ & $61.2 \%$ & $49.4 \%$ & $49.5 \%$ \\
\hline Asia & $8.7 \%$ & $8.6 \%$ & $15.8 \%$ & $13.4 \%$ & $23.0 \%$ & $25.0 \%$ \\
\hline Europa & $59.6 \%$ & $54.3 \%$ & $38.3 \%$ & $19.0 \%$ & $19.3 \%$ & $15.5 \%$ \\
\hline África & $1.0 \%$ & $2.7 \%$ & $3.3 \%$ & $4.1 \%$ & $5.9 \%$ & $6.7 \%$ \\
\hline Oceanía & $0.1 \%$ & $0.0 \%$ & $0.6 \%$ & $0.5 \%$ & $0.5 \%$ & $1.2 \%$ \\
\hline & & & & & & \\
\hline RPCH & $0.1 \%$ & $2.3 \%$ & $1,9 \%$ & $3.0 \%$ & $8.5 \%$ & $7.2 \%$ \\
\hline
\end{tabular}

Fuente: INDEC. Unidad: millones de dólares estadounidenses. Europa incluye Rusia (URSS). 
En cuanto a las importaciones, en 2013 los dos primeros mercados concentraron el $41.4 \%$ de las compras totales. Brasil, con una participación del $26,1 \%$ del total importado, es el principal socio, seguido de China $(15,3 \%)$. Esta última revela una tendencia creciente que, de continuar en los próximos años, podría alcanzar a Brasil. Luego siguen Estados Unidos como socio relevante $(10,9 \%)$, Alemania $(5,3 \%)$, México $(2,9 \%)$ y Francia $(2,8 \%)$.
Las importaciones por continente, al igual que las ventas, muestran el declive estructural de Europa y el ascenso de Asia, también estimulados por la participación de China que, como se expresó, en 2013 representó el 59.3\% de dicho continente. América se mantuvo estable en el $50 \%$ de las compras, lideradas por Brasil, Estados Unidos y en menor medida, México y Bolivia; mientras que África y Oceanía carecen de relevancia.

Cuadro N7: Evolución histórica de los cinco principales orígenes de las importaciones de Argentina.

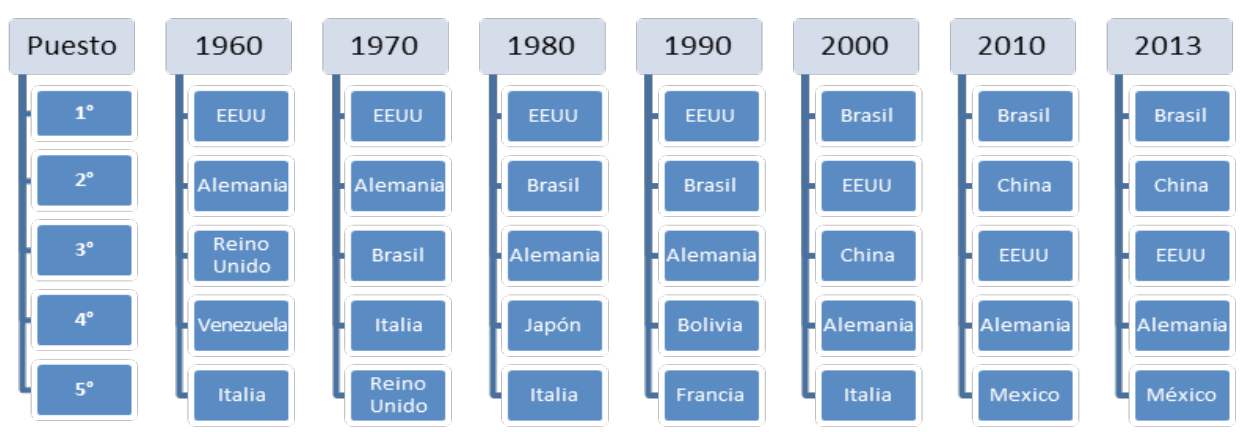

Cuadro N8: Porcentaje de las importaciones argentinas por continentes.

\begin{tabular}{|c|r|r|r|r|r|r|}
\hline Continente & \multicolumn{1}{|c|}{1970} & \multicolumn{1}{|c|}{1980} & \multicolumn{1}{c|}{1990} & \multicolumn{1}{c|}{2000} & \multicolumn{1}{c|}{2010} & 2013 \\
\hline América & $50.5 \%$ & $44.9 \%$ & $56.8 \%$ & $55.2 \%$ & $53.1 \%$ & $49.9 \%$ \\
\hline Asia & $8.1 \%$ & $17.3 \%$ & $7.9 \%$ & $15.8 \%$ & $23.0 \%$ & $25.8 \%$ \\
\hline Europa & $40.4 \%$ & $35.3 \%$ & $32.5 \%$ & $26.8 \%$ & $21.9 \%$ & $22.1 \%$ \\
\hline África & $0.6 \%$ & $1.4 \%$ & $0.5 \%$ & $1.7 \%$ & $0.6 \%$ & $0.9 \%$ \\
\hline Oceanía & $0.1 \%$ & $1.1 \%$ & $2.1 \%$ & $0.3 \%$ & $0.6 \%$ & $0.3 \%$ \\
\hline & & & & & & \\
\hline RPCH & $0.0 \%$ & $0.3 \%$ & $0.2 \%$ & $4.5 \%$ & $13.5 \%$ & $15.3 \%$ \\
\hline
\end{tabular}

Fuente: INDEC. Unidad: millones de dólares estadounidenses. Europa incluye Rusia (URSS). 
Sin duda, la desconcentración de los mercados de exportación mitiga los riesgos de dependencia comercial respecto de algún país en particular. En este sentido, es interesante observar el constante incremento de la participación de China en el comercio exterior argentino. Desde el inicio de relaciones diplomáticas hasta fines de la década de 1970, su participación osciló entre el $0,15 \%$ en 1972 (es decir, su inexistencia) hasta el pico máximo de $2,6 \%$ en 1979. En la década siguiente, el intercambio creció vertiginosamente a un promedio que fluctuó entre el $1 \%$ en 1984 y el 6,4\% del año anterior. La denominada década neoliberal de los años noventa, a pesar de la importación de las llamadas «baratijas chinas», mantuvo niveles de intercambio entre $1,1 \%$ en 1992 y su pico máximo de 3,4\% en 1998. Será en la primera década del siglo XXI cuando el comercio bilateral produjo un salto relevante, aún mayor que el ocurrido en la década de los años ochenta, oscilando entre $4,1 \%$ en 2000 y 10,6\% en 2008 (Oviedo, 2010: 542$545)$. En la segunda década del siglo, mantuvo un promedio del $10,6 \%$ en el periodo 2010-2013.

Ahora bien, Argentina no es una economía que dependa comercialmente de China. Los porcentajes del comercio bilateral son importantes y posicionan a China como su segundo socio estratégico, pero las cifras son aún insignificantes para afirmar tal dependencia. En contrario, se ha mencionado reiteradamente la Brasil-dependencia, no tan así la China-dependencia, pues su primer socio comercial ha mantenido en promedio el $24,3 \%$ para el periodo 2010-2013. No obstante, de continuar la estructura centro-periférica, no solamente con China sino con otros países del mundo, crecerá la dependencia comercial.

\section{g) Punto de inflexión y expansión de las inversiones chinas en Argentina}

La corriente de capitales de las potencias desarrolladas hacia el Este asiático a fines del orden bipolar favoreció al modelo productivo chino, simultáneamente con la «década perdida» de Argentina. La recuperación de las inversiones apareció de la mano del Consenso de Washington, aunque China tuvo ínfima participación en el país sudamericano. Entrado el siglo, el default declarado en 2001 la marginó del sistema financiero internacional y China emergió como oportunidad de financiamiento externo, principalmente por su acumulación de reservas, la internacionalización de sus empresas y la no existencia de tenedores chinos de deuda argentina. No obstante, la potencia asiática consideró esta alternativa, a través de "paraísos fiscales», recién tras el inicio de la crisis de las hipotecas subprime.

A partir de entonces surgen dos momentos importantes en materia de inversiones. El primero, en 2007, cuando el total de las inversiones directas chinas en Argentina superó el total de las inversiones del país sudamericano 
en China. El segundo, en 2010, cuando varias compañías chinas (CNOOC, PetroChina e ICBC) invirtieron en activos relacionados con Argentina. A estas se agrega la ya mencionada compra de Nidera por $\mathrm{COFCO}^{7}$.

Además, mediante compras directas, el gobierno argentino adquirió material rodante para el metro de Buenos Aires y líneas ferroviarias bajo su control. Este canal de «compre chino» sin licitación pública estimula a provincias y municipios que, con el aval del gobierno central, buscan gestionar proyectos con financiamiento chino. Por otra parte, en 2013, el gobierno nacional adjudicó la construcción de las represas Néstor Kirchner y Jorge Cepernic a un grupo económico del cual participa la empresa china Gezhouba. Así, China se posiciona como uno de los importantes inversores en empresas con fuerte presencia en Argentina, pero como estas son realizadas vía "paraísos fiscales", Estados Unidos, Brasil, Suiza y Chile siguen siendo principales inversores en el país, según la Cepal (2012: 58).

Ante la dificultad de acceder al mercado financiero internacional por la persistencia de la situación de default, Argentina acrecienta su dependencia del capital chino, pues este compite a tasas bajas con el europeo,

7 En febrero de 2014, la compañía COFCO anunció la compra del 51 por ciento de Nidera, una corporación holandesa originadora y procesadora de granos y oleaginosas, con fuerte presencia en Argentina, la cual conservará el por ciento de las acciones de la empresa y el control de la compañía. (Naishtat, 2014). americano y japonés. En varios casos China carece de la mejor tecnología, pero sus condiciones de financiación son insuperables para esos países. No obstante, las restricciones cambiarias establecidas por el gobierno de Fernández de Kirchner, desde octubre de 2011, paralizó la corriente de inversiones directas, colocándose las empresas chinas en una posición de wait and see. Además, el distinto valor del dólar en el mercado oficial de cambios y el mercado marginal (ilegal), al menos incrementa en la misma proporción el valor de los proyectos en dólares, pues las empresas chinas deben cambiar sus dólares a pesos en el mercado oficial y contratar personal e insumos locales a precios dolarizados según el mercado paralelo, donde la diferencia entre ambos superó el 60 por ciento a inicios de 2014. Esta situación cambiaria eleva los costos y, por ende, el valor final de los proyectos, aunque es condición similar también para el resto de las empresas extranjeras.

\section{b) Ampliación de la brecha asimétrica y formación de relaciones Norte-Sur}

En 1991, la economía argentina, que equivalía a la mitad de la china, pasó a ser un quinto en 2001 y el 6,1\% en 2011, cayendo al 5,7\% en 2012 (ver cuadro $\mathrm{N}^{\circ} 9$ ). Ese año, China se posicionó en el segundo puesto de la economía mundial y Argentina en el vigesimoquinto, según los PIB a precios constantes. Diferentes del sexto 
y decimosexto puestos ocupados en 2001, respectivamente (ver cuadro $\mathrm{N}^{\circ} 10$ ). Esta situación ha sido constante también en otros socios del Mercosur. Brasil, que en 1991 superaba 7,3\% en tamaño a la economía china, pasó a ser $41,8 \%$ más grande una década después. En 2011 representó un tercio de la economía china en términos de PBI y un quinto en términos de PPA. Similar tendencia sucedió en Paraguay, Uruguay y Venezuela (ver cuadro $\mathrm{N}^{\circ}$ 9).

Esta ampliación de la distancia asimétrica cambió las posiciones de ambos países en la estructura internacional. China emergió como gran potencia económica, miembro del Directorio mundial y cada vez más del Norte; mientras que Argentina se sitúa en la periferia, estabilizada en el Sur, sin ingresar, desde el punto de vista económico, a la categoría de mediana potencia. Asimismo, la ampliación de la brecha también acentuó la caída de Argentina de los primeros puestos que ocupaba en el comercio chino con América Latina y el Caribe. En 2012 se posicionó como sexto socio comercial, sexto destino de sus exportaciones y sexto destino de origen de sus importaciones, según datos del Buró Nacional de Estadísticas de China.

Cuadro $N^{\circ} 9$ : Porcentaje de las economías mercosureñas respecto a China.

En PIB a precios constantes

\begin{tabular}{|l|r|r|r|r|}
\hline \multicolumn{1}{|c|}{ Países } & \multicolumn{1}{c|}{1991} & \multicolumn{1}{c|}{2001} & \multicolumn{1}{c|}{2011} & \multicolumn{1}{c|}{2012} \\
\hline Argentina & $\mathbf{5 0 , 0 \%}$ & $\mathbf{2 0 , 3 \%}$ & $\mathbf{6 , 1 \%}$ & $\mathbf{5 , 7 \%}$ \\
\hline Brasil & $107,3 \%$ & $41,8 \%$ & $33,9 \%$ & $27,3 \%$ \\
\hline Paraguay & $1,6 \%$ & $0,5 \%$ & $0,3 \%$ & $0,3 \%$ \\
\hline Uruguay & $2,9 \%$ & $1,6 \%$ & $0,6 \%$ & $0,6 \%$ \\
\hline Venezuela & $13,6 \%$ & $9,3 \%$ & $4,3 \%$ & $4,6 \%$ \\
\hline
\end{tabular}

Fuente: Elaboración propia en base a datos del Banco Mundial.

PIB (US\$ a precios actuales).

Cuadro N¹0: Lugares ocupados por Argentina y China en la economía mundial.

\begin{tabular}{|l|r|r|r|r|}
\hline \multicolumn{1}{|c|}{ Países } & 1991 & 2001 & 2003 & \multicolumn{2}{|c|}{2012} \\
\hline Argentina & $20^{\circ}$ & $16^{\circ}$ & $35^{\circ}$ & $25^{\circ}$ \\
\hline China & $11^{\circ}$ & $6^{\circ}$ & $6^{\circ}$ & $2^{\circ}$ \\
\hline
\end{tabular}

Fuente: Elaboración propia en base a datos del Banco Mundial. PIB (US\$ a precios actuales). 
Se puede afirmar que, como consecuencia de tasas de crecimiento disímiles, Argentina perdió poder económico relativo y China incrementó la asimetría, conformando relaciones Norte-Sur desde 1999 -año en que China ingresa al oligopolio de poder o Norte desarrollado-, además de descender posiciones como socio comercial de China en Latinoamérica.

\section{i) Creciente influencia china y debilitamiento del vínculo con Taiwán}

Desde 2008, la cuestión de Taiwán se mantiene en statu quo. Ese año, el apartado tercero del Documento sobre Política de China hacia América Latina y el Caribe consagró el respeto al «principio de una sola China» como base política para establecer y desarrollar las relaciones interestatales $(\mathrm{RPCH}, 2008$ : $\mathrm{s} / \mathrm{n})$. Argentina mantuvo constante el respeto a este principio, aun a costa de perder la equidistancia ante la cuestión, hasta inclinarse hacia una posición proclive a la República Popular China (Oviedo: 2012b: 1).
En el vínculo con Taiwán, evitó contactos oficiales, incluso aquellos tolerados por Beijing, como los económicos, a pesar de que otros países latinoamericanos -especialmente Brasil y Chile- desarrollaron importantes interacciones comerciales con la isla. Es decir, más allá del rol económico de China, la política argentina hacia la cuestión de Taiwán priorizó la relación política con la República Popular, posición definida por la búsqueda de apoyo internacional a la cuestión de Malvinas, planteada como trueque, debido al rol que China ejerce en la política mundial, en particular como miembro permanente del Consejo de Seguridad de las Naciones Unidas. Esta orientación política compromete en tiempos de turbulencia, como el periodo 2000-2008, cuando el Partido Demócrata Progresista accedió al poder en Taiwán e intentó ingresar a las Naciones Unidas, oportunidad en que Argentina hizo explícito su apoyo a la República Popular China. Como se observa, la creciente influencia de China ha sido paralela al retroceso de la de Taiwán en el país sudamericano,

Cuadro N¹1: Comercio argentino-taiwanés (2008-2013).

\begin{tabular}{|c|r|r|r|r|}
\hline \multicolumn{1}{|c|}{ Año } & \multicolumn{1}{|c|}{ Exportaciones } & \multicolumn{1}{|c|}{ Importaciones } & \multicolumn{1}{|c|}{ Total } & \multicolumn{1}{|c|}{ Saldo } \\
\hline 2008 & 74 & 402 & 476 & - \\
\hline 2009 & 69 & 291 & 360 & -222 \\
\hline 2010 & 223 & 444 & 667 & -362 \\
\hline 2011 & 177 & 539 & 716 & -207 \\
\hline 2012 & 304 & 511 & 815 & -129 \\
\hline 2013 & 416 & 545 & 961 & -1.469 \\
\hline Total & 1.263 & 2.732 & 3.995 & \\
\hline
\end{tabular}

Fuente: INDEC. Unidad: millones de dólares estadounidenses. 
si bien en los últimos años aumentó el intercambio comercial, con importaciones más dinámicas que las exportaciones, generando crónicos déficits en la balanza comercial (ver cuadro $\mathrm{N}^{\circ} 11$ ).

\section{j) Política proclive a China en derechos humanos}

En discordancia con la política interna, en materia de derechos humanos la política ha sido permisiva frente a las violaciones ocurridas en China. El despliegue del vínculo económico con la potencia asiática y los intereses creados, acotaron el margen de crítica a la situación de los derechos humanos en ese país, como la represión a la comunidad üigur o los problemas en el Tíbet. Sin embargo, el episodio sobresaliente ha sido la "solución política» otorgada a la crisis bilateral de fines de 2009, cuando el juez Octavio Aráoz de Lamadrid emitió una orden de detención contra el ex presidente Jiang Zemin y otros funcionarios del Partido Comunista chino, para que comparecieran en la causa iniciada por torturas y genocidio a practicantes de Falun Gong en China (Oviedo: 2012b: 1). Esta situación es similar a la ocurrida en España, cuando, bajo presión de China, el gobierno de Rajoy decidió limitar la «justicia internacional» sobre los casos de violación de los derechos humanos en el mundo a los ciudadanos españoles (España..., 2014)

Esta política tiene continuidad histórica desde la normalización de relaciones en 1972, pues los intereses económicos son la base de sustentación de la relación política. Así se explica como Argentina, defensora de los derechos humanos desde el retorno a la democracia en 1983, posee un segundo estándar ante la situación de los derechos humanos en China, política coincidente con la mayoría de los miembros de la comunidad internacional que, atraídos por la hegemonía económica introvertida de China, sueñan con tener una mayor participación en este pujante mercado. En su caso, la soja y sus derivados han sido la base de sustentación de la relación económica y, los altos precios de los commodities, mantuvieron un importante nivel de ventas al país asiático, especialmente en la primera década del siglo XXI. Este canal comercial resulta proclive para que Argentina realice una «prudente» política en materia de derechos humanos que redundó en el apoyo a China sobre esta cuestión en la ONU. La «hipocresía de las naciones», que como se dijo no solo afecta a Argentina sino al resto de las potencias, aplica una supuesta política realista de doble estándar en materia de derechos humanos, concretada en el plano interno y omitida en el plano internacional.

Los gobiernos de Menem y De la Rúa condenaron las violaciones a los derechos humanos en Cuba y las omitían en el caso de China; agravado en las gestiones de Kirchner y Fernández de Kirchner, cuando la impronta de la política de derechos humanos en el plano interno no tuvo correlación con el silencio en los casos de Cuba y 
China en el plano internacional. Por eso, ante China, la defensa de los derechos humanos quedó subordinada a la relación comercial y las expectativas potenciales que genera el mercado chino y sus inversiones, aclarando que si la tensión emerge en materia económica, seguramente este tema surgirá al nivel de la interacción política.

\section{k) Deterioro del comercio intra-} zona y otros efectos indirectos vía

\section{Mercosur}

Los países del Mercosur también se integran al modelo chino, pero interrumpieron selectivamente la corriente de libre comercio en productos que podrían perturbar la industrialización de sus miembros. No obstante, como la dinámica económica de China es tan abrumadora e imponente, y el Mercosur no ha constituido una unión aduanera plena, la fuerza de tracción de la economía china integró a sus miembros en su división internacional del trabajo. Este vínculo con la potencia asiática incrementó el comercio extra-zona, con impacto negativo en la integración del bloque, afectando a la Argentina, en la medida que China la desplazó del segundo puesto que ocupaba en las importaciones de Brasil, a pesar de que ambos países del Mercosur tienen proximidad geográfica y un Tratado de Libre Comercio. Las relaciones triangulares entre los dos principales socios del Mercosur y el país asiático también son útiles para descomprimir la Brasil-dependencia del comercio exterior argentino.

Cuadro N¹2: Mercosur: porcentaje del comercio intra-zona, extra-zona y China.

\begin{tabular}{|l|r|r|r|r|r|}
\hline \multicolumn{1}{|c|}{ Año } & \multicolumn{1}{|c|}{1995} & \multicolumn{1}{c|}{2000} & \multicolumn{1}{c|}{2005} & \multicolumn{1}{c|}{2010} & \multicolumn{1}{|c|}{2012} \\
\hline $\begin{array}{l}\text { Porcentaje de las exportaciones } \\
\text { intra-Mercosur }\end{array}$ & 20.2 & 20.6 & 12.8 & 15.6 & 16.5 \\
\hline $\begin{array}{l}\text { Porcentaje de las exportaciones } \\
\text { extra-Mercosur }\end{array}$ & 79.8 & 79.4 & 87.2 & 84.4 & 83.5 \\
\hline Exportaciones totales & 71.609 & 85.929 & 165.270 & 283.343 & 339.509 \\
\hline $\begin{array}{l}\text { Porcentaje de las importaciones } \\
\text { intra-Mercosur }\end{array}$ & 20.5 & 20.1 & 19.4 & 16.6 & 15.1 \\
\hline $\begin{array}{l}\text { Porcentaje de las importaciones } \\
\text { extra-Mercosur }\end{array}$ & 79.5 & 79.9 & 80.6 & 83.4 & 84.9 \\
\hline Importaciones totales & 4.1 & 4.2 & 7.6 & 14.7 & 15.3 \\
\hline $\begin{array}{l}\text { Porcentaje de las exportaciones a } \\
\text { China }\end{array}$ & 2.2 & 3.1 & 7.8 & 14.7 & 15.5 \\
\hline $\begin{array}{l}\text { Porcentaje de las importaciones } \\
\text { a China }\end{array}$ & & 86.622 & 109.341 & 256.479 & 365.257 \\
\hline
\end{tabular}

Fuente: Centro de Economía Internacional, Argentina.

Unidad: millones de dólares estadounidenses. 
En este ABC, Argentina es el eslabón más débil, periférico, frente a dos Estados miembros del Directorio de grandes economías. China es la fuerza propulsora que tracciona directa, e indirectamente vía Brasil, a la economía argentina. La Brasil-dependencia -representada por $21.5 \%$ de las exportaciones y $26.1 \%$ de las importaciones argentinas en 2013- tiene detrás a la economía china, y si agregamos a la potencia asiática, $28.7 \%$ de las exportaciones y $41,4 \%$ de las importaciones argentinas dependen de estos dos mercados, lo que revela la importancia de estas relaciones triangulares para Argentina. A corto plazo, el efecto de arrastre ha sido positivo para su crecimiento, pero en función de los largos ciclos de Wallerstein (1996: 489-502), Argentina se encuentra ahora en una posición más periférica respecto de China de lo que era hace tres décadas y la relación se ha vuelto más asimétrica. Este tipo de interacción muestra la variabilidad en el nivel de industrialización de los dos Estados y, por lo tanto, las diferentes etapas de sus procesos de modernizaciones.
La firma de un Tratado de Libre Comercio fue eje central de la política china hacia el bloque regional. Empero, la política del Mercosur ha sido de constante oposición a este tipo de acuerdos, desde el rechazo a la iniciativa del Área de Libre Comercio de las Américas (ALCA), propuesta por el expresidente George W. Bush. Incluso, en absoluta contradicción con la política china hacia el bloque, el gobierno de Uruguay, a través de su presidente Mujica (2013), propuso "discutir un arancel especial para los productos chinos", pues las industrias de la región «no tienen condiciones para resistir los precios con los que sale China al mundo». Esta idea consiste en generar barreras proteccionistas para reorientar la corriente comercial y contener el impacto de los productos chinos en las industrias locales. No es más ni menos que reflotar la idea de la unión aduanera: la deuda pendiente del Mercosur. Distinta a la propuesta de 2010, cuando en respuesta al «Documento sobre Política de China hacia América Latina y el Caribe», presentado por el gobierno

\section{Cuadro N¹3: Mercosur-China y sus efectos en Argentina.}

- Doble tracción de la economía argentina: directa vía bilateral y terciarizada vía Brasil;

- Búsqueda de China por firmar un Tratado de Libre Comercio con el bloque;

- Pérdida de la unidad de acción del Mercosur frente a China;

- Auge de la diplomacia bilateral de los Estados miembros;

- Incremento del comercio extra-zona con impacto negativo en la integración comercial;

- China desplazó a Argentina de posiciones relevantes en el comercio intra-bloque;

- China se aproxima a Brasil como socio de las importaciones argentinas;

- Formación de relaciones comerciales triangulares: Argentina, Brasil y China. 
Eduardo Daniel Oviedo

El ascenso de China y sus efectos en la relación con Argentina *

chino en 2008, el Mercosur Ampliado ${ }^{8}$ retomó el diálogo con China, trunco desde 2004, con miras a firmar un acuerdo comercial. Sin embargo, hasta el presente, no se ha firmado un Tratado de Libre Comercio con China y el país asiático no ha insistido en esta propuesta a la luz de los resultados de la iniciativa estadounidense.

\section{Conclusión}

Mientras China acorta la distancia económica respecto de Estados Unidos, al mismo tiempo amplía las asimetrías con los países periféricos. Estas últimas son claramente visibles en el vínculo argentino-chino, explicadas por el esquema Norte-Sur, enmarcado tanto en el pensamiento de Wallerstein, como en las llamadas «relaciones verticales» de Stanley Hoffmann?.

En efecto, como resultado de las altas tasas anuales de crecimiento de la economía china y su intermitencia en Argentina, el principal efecto en el país sudamericano fue la pérdida de poder económico relativo y la amplia-

8 Además de los cinco miembros plenos (Argentina, Brasil, Paraguay, Uruguay y Venezuela) el Mercosur incluye a Bolivia, Colombia, Chile, Ecuador y Perú como miembros asociados.

9 Hoffmann (1991: 65) establece tres dimensiones del sistema internacional: «la dimensión horizontal concierne a las relaciones entre los actores principales; la dimensión vertical pertenece a las relaciones entre el fuerte y el débil; y la dimensión funcional se refiere a las áreas cubiertas por relaciones interestatales». ción de la brecha asimétrica con China, conformando relaciones Norte-Sur por sus nuevas posiciones en la estructura internacional, donde China consolida su estatuto de país del Norte, mientras Argentina sigue sumergida en el Sur.

Este tipo de relación vertical emergió en el comercio, bajo el patrón centroperiferia, y se reprodujo en las inversiones, donde Argentina buscó atraer al capital chino, ante el acceso vedado al financiamiento internacional desde la declaración de default de 2001. No obstante, las inversiones comenzaron a ser una realidad concreta después del inicio de la crisis financiera mundial. A su vez, la economía incidió en el plano político, donde China cuenta con mayor influencia en Argentina, expresada en la gestación de una política exterior proclive a la potencia asiática, incluso en temas tan controvertidos como son los derechos humanos.

La modernización en China abrió canales para el abastecimiento de commodities y creó intereses complementarios que expandieron el comercio bilateral. Sin embargo, a pesar de la mayor densidad comercial, la armonía de intereses profundizó el esquema centro-periferia, poniendo límites a los beneficios económicos de Argentina en la relación bilateral. En este modelo, los altos precios internacionales de la soja y sus derivados modificaron los términos del intercambio a favor del país sudamericano y facilitaron la compra de mayor cantidad de manufacturas y equipos, sin cambiar su estructura 
económica, a diferencia de la industrialización en China.

La venta de la soja y otros agrocommodities amplió el porcentaje de participación de la agricultura en el PBI, que por su alta composición en las exportaciones hacia China consolidó la primarización sojera en la relación. Sin embargo, en el contexto de la actual política comercial argentina, la compra de porotos de soja parece haber llegado a su techo. En 2012, China adquirió el $80 \%$ de las ventas totales, las cuales representaron solo el $20 \%$ de la producción nacional, al industrializar el 80\% restante. Al comprar casi todo el grano, paralizó las exportaciones desde 2007, sin lograr superar hasta el presente el pico de 6.397 millones de dólares de 2008. A su vez, el crecimiento de las ventas chinas, que alcanzaron 11.362 millones en 2013, generó déficit por 18.500 millones entre 2008 y 2013, equivalente a la caída de las reservas argentinas en el mismo periodo; con la paradoja de que, durante la visita del presidente Xi Jinping a la Argentina en julio de 2014, el Banco Popular de China y el Banco Central de la República Argentina renovaron el acuerdo swap renminbí/peso por 11.000 millones de dólares.

Revertir los saldos desfavorables es una ardua tarea en el contexto macroeconómico actual de la Argentina y para incrementar las exportaciones requiere echar mano a otros commodities, ya que los productos industriales tienen escasa participación en el intercambio y no pueden cambiar abruptamente la tendencia comercial. Precisamente, la "primarización sojera", consolidada desde 2002, transita hacia la "primarización agrícola diversificada", a partir de la firma de protocolos sanitarios (tabaco, maíz, cebada, sorgo) que permitirán expandir las ventas a través de otros commodities que el mercado chino requiere. Es decir, construye la diversificación de corte horizontal, no vertical, en la medida en que la política comercial china está orientada a la compra de productos primarios. Pero, como Argentina busca agregar valor, es aquí donde las dos modernizaciones económicas se enfrentan con políticas comerciales antitéticas.

Los commodities han sido parte de la estrategia que financió al gobierno y es factor principal para equilibrar el intercambio comercial. Sin embargo, no pueden constituir el eje central a largo plazo, como se ha llevado a cabo hasta el presente, pues seguiría vigente el intercambio centro-periférico, en lugar de avanzar hacia un modelo intraindustrial. Hace tiempo, Raúl Prebisch (1949), Samir Amin (1973) y otros autores estructuralistas se refirieron a la inequidad de este modelo, pero en el caso bajo estudio, la historia se repite. Además, el alto precio de la soja y de otros commodities conspira contra esta alternativa de cambio, en la medida que la percepción de impuestos a las exportaciones resulta una herramienta sencilla de financiamiento para el gobierno nacional, fortalece los intereses de los exportadores de granos que, en asociación con importadores de pro- 
ductos chinos y el propio gobierno, están satisfechos con este tradicional modelo. Solo los productores agrarios, el mundo académico libre ${ }^{10}$ y los industriales locales, que ven perder una cuota del mercado doméstico a manos de los productos chinos, son críticos de este esquema, entendiendo la necesidad de cambio. Finalmente, la relación tuvo baja conflictividad, aunque es creciente y existe cierto desencanto de las potencialidades del mercado chino.

\section{BibliografíA}

Amin, Samir (1986). El desarrollo desigual [1973]. Buenos Aires: Planeta-De Agostini.

10 En la especialidad de las relaciones internacionales, el mundo académico libre es aquel que trasciende la dicotomía entre conocimiento científico e interés nacional, posicionándose en defensa del primero en desmedro de su condición nacional. Por tal motivo quedan excluidas las visiones oficiales, pues el gobierno y sus intelectuales orgánicos poseen intereses creados en continuar este esquema tradicional; así como los estudios escritos por académicos financiados o relacionados con el capital chino. ¿Es posible estudiar en algún Instituto Confucio los graves problemas de derechos humanos en China cuando el mercado chino aparece atractivo para los intereses comerciales y financieros de los países? La respuesta concreta es que resulta casi imposible. El corte de los vínculos o cierre de algunos Institutos Confucios en Estados Unidos y Canadá está demostrando que es incompatible la política china de crear institutos con investigación científica y libertad académica. Para más detalles sobre los Institutos Confucios en Argentina, ver Oviedo (2010, 492-494).
Banco Mundial. Datos estadísticos. www. bancomundial.org

Bernal-Meza, Raúl (2005). América Latina en el Mundo. El pensamiento latinoamericano y la teoría de las relaciones internacionales. Buenos Aires: Nuevohacer.

Buró Nacional de Estadísticas de la República Popular China. Estadísticas de Comercio Exterior. www.stats.gov.cn

Centro de Economía Internacional. Estadisticas, Buenos Aires. www.cei.gov.ar

CEPAL (2012). La inversión extranjera directa en América Latina y el Caribe. Santiago: Cepal.

CEPAL (2013). Promoción del comercio y la inversión con China: desafíos y oportunidades en la experiencia de las cámaras empresariales latinoamericanas. Santiago: Cepal.

«España eliminó la «justicia universal»y dejará de actuar en casos foráneos», en diario Ámbito Financiero, Buenos Aires, 11 de febrero de 2014.

Ferrari, Gustavo (1983). Esquema de la politica exterior argentina. Buenos Aires: EUDEBA.

Hoffmann, Stanley (1991). Jano y Minerva. Ensayos sobre la guerra y la paz. Buenos Aires: Grupo Editor Latinoamericano.

Huang Shuo Feng (1992). Teoría del poder nacional integral. Ciencias Sociales: Beijing, (en chino).

INDEC (2012), Anuario de Comercio Exterior. Buenos Aires: Indec.

INDEC (2003-2014), INDEC Informa. Buenos Aires: Indec.

Keohane, Robert (1988). Después de la Hegemonía. Cooperación y discordia en la política económica mundial. Buenos Aires: Grupo Editor Latinoamericano.

«Mujica propondrá arancel externo común para China», en diario Ámbito Financiero, Buenos Aires, 10 de julio de 2013.

Naishtat, Silvia. "Los chinos se quedan con una de las mayores cerealeras argentinas», en diario Clarín, suplemento Ieco, Buenos Aires, 27 de febrero de 2014.

Oviedo, Eduardo Daniel (2005). China en Expansión. La política exterior desde la 
normalización chino-soviética hasta la adhesión de China a la OMC (1989-2001). Córdoba: EDUCC.

Oviedo, Eduardo Daniel (2010). Historia de las Relaciones Internacionales entre Argentina y China, 1945-2010. Buenos Aires: Dunken.

Oviedo, Eduardo Daniel (2012a). «Argentina y China: causas de la disputa en torno al aceite de soja». En Estudios de Asia y África, Vol. XLVII, N¹48, pp. 337-376.

Oviedo, Eduardo Daniel (2012b). "Argentina y el principio de una sola China». En Cuadernos de Trabajos del CECHIMEX, Universidad Nacional Autónoma de México, $\mathrm{N}^{\circ} 6$, pp. 1-8.
Perotti, Estrella (2008). «¿Qué es el margen bruto de procesamiento?». Rosario: Dirección de Informaciones y Estudios Económicos de la Bolsa de Comercio de Rosario. Disponible en: http://www.bcr. com.ar/Pages/Publicaciones/seriesDet. aspx?ID=38 [Consulta realizada el 1012-2014].

Prebisch, Raúl (1949). El desarrollo económico de la América Latina y algunos de sus principales problemas. Nueva York: Cepal.

República Popular China (2008). Documento sobre Politica de China hacia América Latina y el Caribe. Beijing.

Wallerstein, Immanuel (1996). El moderno sistema mundial. Madrid: Siglo XXI. 